\title{
Identificación de Bacilos Gram negativos Anaerobios y Clostridium a través de los Métodos de API y Minitec 1
}

\author{
Charles W. Hansun, Rodrigo Cassorla,' Willianz J. Martin. ${ }^{1,2}$
}

\author{
API and Minitek Systems in Identification of Clinical Isolates of Anaerobic \\ Gram-Negative Bacilli and Clostridium Species
}

\begin{abstract}
A comperison of the API und Minitek methods of biochemical testing was made on a variety of anaerobic bacteria. Although API and Minitek results were not compared to mone standardized or conventional procedures of identification, multiple repeat testing of the two systems was done on routine clinical isolates and known organisms to determine (i) whether the reactions were reliably consistent, (ii) the ease of reading the two systerns with respect to the frequency of questionable results, and (iii) the percentage of routine clinical isolates for which each system vielded an identificatlon. The Minitek system gave a much lower incidence of difficult to interpret reactions. The two systems were comparable in terns of reproducibility and capability of yielding an identification of the anaerabic grarn-negative bacilli and Clostridium species, but were unsatisfactory for ruotine use on most of the other anaerobic bacteria isolated.
\end{abstract}

La potencial severidad de las infecciones por gérmenes anaerobios ha establecido la necesidad de una identificación rápida y correcta de los organismos involucrados, lo que a su vez permite un tratumiento antimicrobiano adecuado y precoz. Los estudios binquímicos convencionales de anaerobios son lentos y caros y están más allá de las capacidades de demasiados Laboratorios Químicos. Esta necesidad de un sistema simplificado ha llevado al desarrollo de varios procedimientos miniaturizados. Nuestro propósito fue evaluar 2 sistemas de interés, el método de API (Analytab Products, [nc, Plainview, N.Y.) y de Minitec (BBL Microbiology Sistems, Cockeysville, Md.) para determinar su utilidad en la identificación de bacterias anaeróbicas. Especialmente, pruebas repetidas de los procedimientos fueron hechas en aislados clínicos nutinarios para determinar: 1 . Si estas reacciones eran confiablemente consistentes. 2. Precisión de lectura, en lo que se refiere a la frecuencia de resultados dudosos. 3 . El porcentaje de aislados clínicos para el cual cada sistema era capaz de entregar una identificación.

No está dentro de los propósitos de esta investigación comparar el API y el Minitec con los procedimientos tradicionales, ya que esto ha sido hecho en otras publicaciones. ${ }^{6,14}$, 14, 20 Nuestra preocupación básica son los resultados ambiguos

\footnotetext{
1Reimpresión de un articulo publicado en: Joumal ot Clinical nicrobiology July 1979. pp. 14-18.

${ }^{2}$ Departments of Pathology, and Microbiology and Immurology, Clinical Labnratory. Microbiolog: Section, UCiL A Center for the Heitth Sciences, Los Augeles, California 90024 .
}

y conflictivos que se encuentran en el uso diario de los procedimientos en los Laboratorios de Microbiología.

\section{MATERLAL Y METODO}

\section{Organismos y tratamiento de los cultivos.}

Los organismos usados fueron aquellos aislados del trabajo clínico habitual y algunos cultivos de la colección de la Universidad de Califomia, sede Los Angeles. El tratamiento de los cultivos ${ }^{3,12,13} \mathrm{y}$ Ios medios ${ }^{7}$ han sido previamente descritos.

Cada aislado fue inoculado sobre la mitad de una placa de agar sangre para anaerobios ${ }^{7}$ y fue incubado anaeróbicannente a 35 grados centígrados en un jarro Gas-Pak. Una placa comercial de agar sangre fue también inoculada e incubada aeróbicamente a $35^{\circ}$ para servir como control de contaminación. Después de 48 horas de incubación las colonias fueron cosechadas con una tórula de algodón estéril.

\section{Inoculación, Incubación y Lectura de la cinta de} API.

Las bacterias fueron dejadas en suspensión agitando la tórula de algodón en una ampolla de inoculación hasta alcanzar una densidad de aproximadamente 1 x $10^{\circ}$ y con posterioridad fueron inoculadas a las cintas de API de acuerdo a las instrucciones del tabricante.

Las cintas fueron incubadas anaerbbicamente a $35^{\circ}$ en los jarros Gas-Pak. Después de 48 horas fueron retiradas de los jarros, agregándose indica- 
dor de bromocresol púrpura al 0,02 a todos los sustratos de carbohidrato o alcohol antes de la lectura.

El color púrpura fue interpretado como negativo y el amarillo como positivo.

Reacciones dudosas que no eran claramente amarillas o púrpura fiteron interpretadas cono \pm . Todos los demás ensayos fueron realizados de acuerdo a las indicaciones de los fabricantes.

\section{Inoculación, Incubación y Lectura de las bande-} jas de Minitec.

Los organismos fueron suspendidos agitando la tórula de algodón en una ampolla de medio de inoculación para Minitec a una densidad de aproximadamente $5 \times 10^{9}$ células $\times$ ml. La pipeta de Minitec fue usada para inocular los discos de papel filtro que contienen los sustratos en eshudio. Estas placas fieron incubadas en jarros Gas-Pak a $35^{\circ}$.

Después de 48 horas estas placas fueron retiradas de los jarros agregándose indicador de rojo fenol a $0,025 \%$ a todos aquellos sustrates con alcohol $y$ carbohidratos inmediatamente antes de la lectura. El color rojo fue valoradocomo negativo y el amarillo como positivo. Reacciones equívocas en las cuales ni el color amarillo ni el rojo estaba claramente definido fueron interpretados como \pm .

Con ambos sistemas la hidrólisis de la Esculina fue determinada por la ausencia de fluorescencia al ser expuesta a la luz ultravioleta de $360 \mathrm{~nm}$. Controles de viabilidad y de contaminación fueron efectuados simultáneamente en cada organismo estudiado, inoculando 2 placas de agar sangre tanto aeróbica como aneróbicamente. Los resul- tados fueron interpretados de acuerdo a las tablas de identificación entregadas con anbos sisternas.

En aquellas situaciones en las cuales una idertificación de género especie no fue posible con un determinado microsistema o cuando había desacuerdo entre ambos sistemas o ambas situaciones, el género correcto fue determinado usando a tinción de Gram., morfología celular a partir del tioglicolato, presencia o ausencia de esporas, cromatografía y estudios bioquímicos similares a aquellos sugeridos por Porschen y Stalons. ${ }^{17}$

Nuestros resultados fueron reevaluados a la luz de un índice analítico entregado por API.

\section{RESULTADOS}

Una evaluación preliminar de los métodos de API y Minitec fue hecha en 114 organismos conocídos y los resultados comparados con el manual de laboratorio para anaerobios del Instituto Politécnico de Virginia. Los resultados obtenidos con el Minitec y en especial con el API generalmente están de acuerdo con los datos del Instituto Politécnico de Virginia. Sin embargo, se hizo evidente que la comparación de resultados de un sistema con el otro no era estrictamente válido, debido a las diferencias entre ellos en lo referente a uso de butfers, indicadores de PH, y el tamaño del inóculo de ambos procedimientos. Pese a éstas consideraciones Minitec utiliza las tablas del CDC.

Más aún, al usar este enfợue en un número limitado de organismos desconocidos, la frecuencia de identificación no fue mayor que cuando los resultados obtenidos de cada sistema fueron comparados con sus propias tablas de identificación.

Se hizo evidente en las etapas iniciales de este

Tabla 1

Reproductibilidad de reacciones sobre sustratos que afecta identificación final a nivel de géneto especie.

$\begin{array}{ll}\text { Organismo N. }{ }^{D} \text { de organismos } & \begin{array}{r}\% \text { de acuerdo } \\ \text { tests múltiples }\end{array}\end{array}$

\begin{tabular}{lccc}
\hline & & API & MINITEC \\
Clostridium species & 58 & 92,0 & 85,0 \\
Bacteroides species & 84 & 95,5 & 95,8 \\
Fusobacterium species & 21 & 91,3 & 89,5 \\
Cocos gram positivos & 17 & 93,7 & 96,3 \\
Bacilos gram positivos no & 17 & 90,4 & 89,8 \\
formados de espora & & 92,6 & 91,3 \\
Promedio total & & &
\end{tabular}


estudio que en un número significativo de oportunidades, las pruebas repetidas del mismo organismo con ambos procedimientos no daba consistentemente los mismos resultados, debido a la variabilidad entre las reacciones de los sustratos. 197 aislados clínicos fueron evaluados con ambos métodos en lo que se refiere a la facilidad de lectura $y$ reproductibilidad de resultados con el mismo organismo.

Los sustratos usados fieron los siguientes: Indol, Urea, Glucosa, Manitol, Lactosa, Sacarosa, Maltosa, Salicina, Xilosa, Arabinosa, $\mathbf{H}_{2} \mathrm{~s}$, Esculina, Glicerol, Celobiosa, Manosa, Rafinosa, Sorbitol, Raminosa, Trehalosa. La gelatina y la Melesitosa no estaban presentes en el API.

La Tabla 1 presenta los porcentajes de reproductibilidad obtenidos con pruebas repetidas del mismo organismo con un mínimo de tres veces en días diferentes. Poca diferencia fue observada entre ambos métodos. La reproductibilidad mostró ser buena en lo que se refiere a Bacteroides, pero menor en lo que se refiere a otros géneros de bacterias anaeróbicas. Los sustratos que más frecuentemente daban resultados variables con el método de API fueron el Indol, Xilosa, Esculina y Trealosa, y con el Minitec la Salicina, el $\mathrm{H}_{2} \mathrm{~s}$, la Esculina la Celobiosa, Rafinosa y Trehalosa habitualmente entregaron resultados variables. En ambos casos la variabilidad de estas reacciones afectaban la identificación final.

La Tabla 2 muestra el porcentaje de lecturas dudosas observadas con ambos sistemas. Estos datos indican que eI sistema de API tiene un mayor grado de variabilidad, requiriendo que el observador efectúe una evaluación subre la reacción en términos de positivo y negativo. En este aspecto, este problema estaba presente en prácticamen- te todos los sustratos del sistema API. En el Minitec los sustratos más habitualmente involucrados en esta evaluación eran Indol, Manitol, Maltosa, Salicina, Xilosa, Arabinosa, Glicerol, Celobiosa, Sorbitol, Raminosa y Trehalosa.

Sólo en forma excepcional se utilizó el API y el Minitec en la identificación de cocos anaeróbicos $y$ bacilos gram positivos no formadores de espora. Nuestro laboratorio ha eliminado la evaluación de estas bacterias anaeróbicas excepto en un pequeño número de casos debido a un muy bajo porcentaje de éxitos favorables.

Es por lo anterior que nuestros esfuerzos estuvieron orientados hacia los bacilos gram negativos anaerobios y a los clostridium.

Se hicieron intentos de identificar a 272 aislados clínicos de bacterias anaeróbicas usando cada uno de los dos sistemas para cada aislado. Los resultados de cada evaluación fueron interpretados a partir de las tablas de identificación entregadas con el sistema usado.

Los datos que se presentan en la Tabla 3 informan sobre el número de cepas de cada género y el porcentaje del cual obtuvo una identificación. API dio un porcentaje levemente superior de identificación a excepción del género fusobacterium en cuyo caso el sistema Minitec fue superior, debido básicamente a la reproductibilidad de si reacción de Indol.

La Tabla 4 muestra el porcentaje de incapacidad de los dos procedimientos para identificar bacterias anaeróbicas. El porcentaje de aislados identificados por uno u otro de ambos métodos se da en la columna de la derecha. Debe ser enfatizado que las cifras en esta columna no están orientadas a sugerir que uno u otro sistema dio la identifícación currecta, sino que solamente dentro de

Tabla 2

Porcentaje de lecturas dudosas observadas con cada sistema con los siguientes grupos de anaerobios

\begin{tabular}{|c|c|c|c|}
\hline \multirow[t]{2}{*}{ Organismo } & \multirow[t]{2}{*}{ N. de organismos } & \multicolumn{2}{|c|}{ ic de lectura dudosa } \\
\hline & & API & MINITEC \\
\hline Clostridium species & 58 & 4.8 & 3.9 \\
\hline Bacteroides species & 84 & 4.5 & 2.2 \\
\hline Fusobacterium species & 21 & 8.5 & 2.3 \\
\hline Cocos gram positivos & 17 & 7.1 & 0.6 \\
\hline Antinomyees species & 3 & 7.5 & 1.5 \\
\hline Eubacterium lentum & 5 & 4.8 & 1.0 \\
\hline Promedio total & & 6.2 & 1.9 \\
\hline
\end{tabular}


Tabla 3

Anaerobios identificados por API y Minitec

\begin{tabular}{|c|c|c|c|c|c|c|}
\hline \multirow[t]{2}{*}{ Organismo } & \multicolumn{2}{|c|}{ N.'cepas } & \multicolumn{2}{|c|}{ N. ${ }^{\circ}$ cepas identificadas } & \multicolumn{2}{|c|}{$\%$ identificado } \\
\hline & APl & Minitec & API & Minitec & API & Minitec \\
\hline Bacteroides species & 194 & 194 & 118 & 112 & 61 & 58 \\
\hline Clostridium species & 34 & 34 & 16 & 15 & 47 & 44 \\
\hline Fusobacterium species & 16 & 16 & 1 & 8 & 6 & 50 \\
\hline Peptucoceus species & 9 & 9 & 3 & 3 & 33 & 33 \\
\hline Peptostreptococcus species & 7 & 7 & 0 & 0 & 0 & 0 \\
\hline $\begin{array}{l}\text { Anaerobios gram positivo no forma- } \\
\text { dores de espora }\end{array}$ & 10 & 10 & 0 & 0 & 0 & 0 \\
\hline $\begin{array}{l}\text { Bacilos gram negativos no identifi- } \\
\text { calbles. } \\
\% \text { promedio identificado }\end{array}$ & 2 & 2 & 0 & 0 & $\begin{array}{r}0 \\
51\end{array}$ & $\begin{array}{r}0 \\
51\end{array}$ \\
\hline
\end{tabular}

\section{Tabla 4}

Capacidad de API y Minitec para identificar anaerobios

\begin{tabular}{|c|c|c|c|c|c|}
\hline Organismos & Nocepas & $\begin{array}{l}\text { API Minitec en } \\
\text { desacuerdo }\end{array}$ & $\begin{array}{c}\text { API y Minitec } \\
\text { de acuerdo pero } \\
\text { sin identificación }\end{array}$ & $\begin{array}{l}\text { API y Minitec } \\
\text { de acuerdo en } \\
\text { identificución }\end{array}$ & $\begin{array}{l}\% \text { identificado } \\
\text { por cada sistema }\end{array}$ \\
\hline Bacteroides species & 194 & 34 & 75 & 85 & 61 \\
\hline Fusobacterium species & 16 & 8 & $\mathbf{5}$ & 3 & 69 \\
\hline Clostridium species & 34 & 2 & 18 & 14 & 47 \\
\hline Peptococcus species & 9 & 0 & 7 & 2 & 22 \\
\hline $\begin{array}{l}\text { Peptostreptoceus species } \\
\text { Anaerobic, gram positive, non }\end{array}$ & 7 & 0 & 7 & 0 & 0 \\
\hline sporeforming bacilli & 10 & 0 & 10 & ) & $\begin{array}{r}0 \\
54\end{array}$ \\
\hline
\end{tabular}

Tabla 5

Poreventaje de Bacilos gram negativos y clostridinn identificados con API

\begin{tabular}{lccc}
\hline Género & & \multicolumn{2}{c}{ Cepas identificadas con: } \\
Intex analítico
\end{tabular}

este esquema de trahajo se logró una identificación.

Poco después de haber completado esta investigación, API ha entregado un indice de perfil analítico considerablemente ampliado. A la luz de esta nueva infonmación ntiestros resultados de 140 bacilos gram negativas y clostridium fueron reevaluados. La Tabla 5 muestra que el éxito favorable de la identificación mejoró aproximadamente en $18 \%$ sobre lo que habiamos obtenido previamente con el índice original: En detalle, 13\% de rnejoríd para las especies de clostridium, un $22 \%$ en los bacteroides y aparentemente un $20 \%$ con los muy escasos fusobacterium estudiados. 


\section{DISCUSION}

Numerosos investigadores han evaluado test miniaturizados para la identificación de bacterias anaeróbicas. ${ }^{6,14,18,80}$ Muchos de los organismos usados en estos estudios eran anaerobios nuy bien definidos y característicos, obtenidos de colecciones de los laboratorios. ${ }^{14 .}$ 16. 20 La comparación de API Minitec y métodos convencionales a veces resiltaba en más de un $90 \%$ de concordancia. Sin embargo, nuestra experiencia apunta a un mucho nuenor porcentaje de identificación, al nivel de especie, si se trabaja con muestras clínicas incógnitas enviadas al laboratorio para su identificación. Una revisión preliminar de nuestros resultados con el método de API de 568 aislados clinicos de bacilos gram negativos y clostridium mostraron un porcentaje de eficacia del orden del 50\%. El índice analítico reciente del método de API parece ofrecer ciertas esperanzas en este aspecto, ya cue parece proporcionar un mayor percentaje de identificación a nivel de especie, a pesar de que algunos de estos aislados tienen gran porcentaje de variabilidad individual.

Evaluaciones de reproductibilidad han sido efectuadas con sistemas miriaturizados, diseñados básicamente para su uso con bacterias facultativas, ${ }^{2, \mathrm{~h}, 11}$ estas evaluaciones también encontraron resultados diversos al reiterar las pruebas con el mismo aislado. Por ejemplo, en un estudio ${ }^{2}$ sólo el $\mathbf{5 5 \%}$ de los aislados dio reacciones idénticas en priebas reiteradas con el método de API, pero se obtuvo un $97,9 \%$ de identificación a nivel de género especie, lo que se debe probablemente al mayor número de enterobacteriáceas involucradas. A la luz de estos datos, el $90 \%$ de reproductibilidad obtenido con bacterias aneróbicas no es un problema considerable, sino uno debe basarse eu tablas simplificadas de estos sistemas. Muchos desacuerdos en la identificación a nivel de especie fueron debidos a las lecturas dudosas de los distintos sustratos bioquímicos. Mínitec tuvo un mejor rendimiento en este aspecto, lo que es probablemente atribuible a la mayor densidad microbiana $\left(5 \times 10^{4}\right)$ que requiere para su inóculo. Apoyando este planteamiento, la incubación anaeróbica no es necesaria tanto con el API como con el Minitec para identificar un bacteroides fragilis, lo que sugiere que a una deterninada densidad bacteriana la actividad enzimática residual puede ser más importante que la multiplicación microbiana, para la utilización de los sustratos. (16 datos no publicados).

Cuando los sustratos de API o del Minitec estaban en desacuerdo o cuando estaban de acuerdo en la identificación de un determinado aislado no nos sentimos obligados a buscar una identificación inequívoca a través de métodos estandarizados o convencionales. Considerando las exigencias de un laboratorio clínico nomal nuestro objetivo era simplemente determinar cuál de los 2 procedimientos más frecuentemente entregaba una identificación. Sólo el $\mathbf{5 0 \%}$ de las bacterias anaeróbicas estudiadas fueron identificadas por uno u otro sistema y en el.16\% de estos casos el API y el Minitec estaban en desacuerdo en su identificación.

No parece razonable esperar total acuerdo entre ambos métodos estudiados o con algún otro sis. tema empleado, dado que las condiciones de ensayo en cualquier procedimiento pueden diferir de aquellas usadas en otros. ${ }^{14}$ De tal manera, reacciones bioquimicas identicas obtenidas de un determinado organismo usando diferentes sistemas no parecen lógicas de esperar. Sin embargo, estos sistemas deben ser internamente reproductibles $\mathrm{y}$ sus tablas de identificación suficientemente completas como para permitir una identificación satisfactoria de la nayoria de las bacterias obtenidas de muestras adecuadas. El desacuerdo entre varios sistemas es un problema mayor en la comparación de resultados entre distintos laboratorios, pero pueden no ser serias sobre la base de un solo laboratorio si se usa el mismo procedimiento, en forma consistente, y los resultados son reproductibles. Este criterio no ha sido resuelto satisfactoriamente. Sin embargo, el nuevo índice analítico del API ha mejorado esta identificación a un aceptable $68 \%$.

Algunos investigadores han argumentado que no es necesario identificar completamente todas las bacterias anaerobicas. Sin embargo, este planteamiento es contrario a los fundamentos de una microbiología bien entendida. ${ }^{10} \mathrm{Y}_{\text {a }}$ que existen numerosos tests y éstos pueden realizarse en cierto grado de flexibilidad, este argumento contrario a la identificación completa hasta el nivel de especie pierde gran parte de su significado.

En general nuestros resultados muestran que con algunas de las bacterias anaeróbicas más frecuentemente aisladas y de rápido creciniento ambos tests son satisfactorios obteniendo ventaja el método de API debido a un nuevo indice analiti- 
co. Sin embargo, cada sistema mostró una menos que satisfactoria capacidad de identiticar a aquellos anaerobios de lento crecimiento o exigentes o ambos. Esta diferencia probablemente thene una relación directa con la incapacidad de estos organismos de lento crecimiento, para alcanzar una densidad de inóculo adecuada para la utilización optima de los sustratos en cada sistema. Afortunadamente las bacterias anaeróbicas, para las que estos sistemas son apropiados, son aproximadamente el $50 \%$ de las bacterias de importancia clínica assladas en un laboratorio de anaerobios.

\section{REFERENCIAS}

I Blank, F.C. Identification of anaerobic bacteria. Letter to the editor. Ars. Soc. Microbiol. News 42: 393-394, 1976.

2 butier, D.A., C.M. Tobrekat, and T.L. Cavan. Reproducibility of the Analytal, (API 20 E) system. J. Clin. Micrubiol. 2 : 322-326, 1975.

${ }^{3}$ Dowell, V.R., and T.M. Hawkins. Iahoratsry methods in anderubic bucteriology. Center for Disease Control. Atlanta, $\mathrm{G}$, 1974.

dFinegold, S.W., J. Bartlet, A.W. Chow, OJ. Flora, S.L. Garbach, E.J., Horder, and F.P. Tally. UCLA Conference. Management of inaerobic infections. Ann. lntem Med, 83: 375$389,1975$.

${ }^{5}$ Gorbach. S.Ln, and J.G. Bartiett. Medical progress: an aerolbic infections. N. Engl. J. Med. 290; 1177-1184-1237-1244, 12891294, 1974.

6 Hunsen, S.L., and B.J. Stewart. Cómparison of API and Miritek to Center for Disease Conbol methods for the biochemical charucterization of anaerobes. J. Clin. Microbial. 4: $227-231,1976$.

7 Hanson, C.W., and W. Martir. Evaluation of emrichernent, storage, and age of block agar medium in relation to its ability to support growth ol anaerobic liacteria. J. Clin. Micrabiol. 4: $344-399,1976$.
"Hanyon, C.W., F. Marso, and W.J. Martin. Comparisom of the Minitek test system with a conventional screeniug procedure for identification of Enterobacteriaceae. Health Lab. Science. 15: $3-8,1978$.

${ }^{9}$ Holdemon, L.V., E.P. Cato and W.E.C. Moore. Anaerobic hacteriolingy manual. Anaerube Labontory, Virgnia Polytechuic Institute and State University, Blacksburg, Va, 1977.

10 Hokdeman, L.V. Identification of clinical bacteria Letter to the editor. Am. Sinc. Microbiol. News 42: 264-265, 1976.

11 Holmes, B., W.A. Wilcox, S.P. La Poge, and H. Molnick. Test reproducibility of the API (20 E), Enterotube, and Pathotek systems. J. Clin. Pathol. 30: 381-387, 1977.

12 Martin, W.J. Practical methol tor isolation of anerobic bacteria in the elinical laboratory: Appl. Microbiol. 22: $1168-$ $1171,1971$.

13 Martin, W. J Insolation and identification of anaerobic bacteria in the clinical faboratory. Mayo Clin. Proc. 49: 300-308, 1974.

14 Moore, H.B., V.L. Sutter, and S.M. Finegold. Comparison of three methods for biochemical testing of anaerobic bacteria. J. Clin. Microbiol. 1: 15-24, 1975.

15 Porschen, F.K., and D.R. Sialons. Evaluation of simplified dichotomous schemata for the identification of anerobic bacteria from clinical material. J. Clin. Microbiol. 3: 161-171, 1976.

16. Schreckenberger, P.C., and DJ, Blazevic. Rapid fementation testing of anaerobic bacteria. J. Clin. Microbiol. 3: 313-317. 1976.

17 Stalons, D.R., and H.K. Porschen. Identification of anaerobic hacteria. Letter to the editor. Am. Soc. Microbisl News 42 . $393,1976$.

1 is Stargel, M.D., F.S. Thompson, S.E. Phillips. G.L. Lombard, and V.f. Douctl,Jr. Modification of the Minitek mimiaturized differentiation system for characterization of anaerobic bacteria. J. Clin. Microbiol. 3: 291-301, 1976.

14 Stargel, M., D.G.L. Lombard, and V.R. Dowell. Alternative procedures for identification of anaerobic-bacteria. Am. J. Med. Technol 44: 709-722, 1978.

${ }^{20}$ Start, S.E., F.S. Thompson, V.R., Dowell, Jr., and A. Balows. Micromethod system for identification of anaerobic bacteria. App. Microbiol. 25: 713-717, 1873. 